\title{
Innovating Configuration and Mechanic Properties of Ultralight and Porous Quasi-Square-Honeycomb Sandwich Structure' Core
}

\author{
Li Xiang ${ }^{1,2,3}$, Zhou Youhui ${ }^{2}$, Tong Guan ${ }^{2}$, Wang Yang ${ }^{2}$, Yang Zhihao ${ }^{2}$ \\ ${ }^{1}$ Hubei Key Laboratory of Hydroelectric Machinery Design \& Maintenance, China Three Gorges University, Yichang, China \\ ${ }^{2}$ College of Mechanical and Power Engineering, China Three Gorges University, Yichang, China \\ ${ }^{3}$ Hubei Provincial Collaborative Innovation Center for New Energy Microgrid, China Three Gorges University, Yichang, China
}

\section{Email address:}

lixiangcfy@163.com (Li Xiang)

\section{To cite this article:}

Li Xiang, Zhou Youhui, Tong Guan, Wang Yang, Yang Zhihao. Innovating Configuration and Mechanic Properties of Ultralight and Porous Quasi-Square-Honeycomb Sandwich Structure' Core. American Journal of Mechanical and Industrial Engineering.

Vol. 2, No. 5, 2017, pp. 198-204. doi: 10.11648/j.ajmie.20170205.12

Received: February 2, 2017; Accepted: February 28, 2017; Published: November 28, 2017

\begin{abstract}
A continuous interest for an extensive use of sandwich structures in automotive, aerospace and civil infrastructure has been manifested in the last years due to the main advantage of lightweight and energy absorption ability. Based on characteristics of press molding process of honeycomb sandwich structure, a new kind of quasi-square honeycomb sandwich structure is proposed. Following classical unit cell theory and energy method, the mechanical equivalent model of the quasi-honeycomb sandwich structure is established and the corresponding equivalent elastic constant formula is deduced. Taking a sandwich panel in a satellite structure as an example, from the aspect of core characteristics, mechanical properties, equivalent elastic constants of honeycomb sandwich structure, and shear modulus, the differences between square honeycomb and quasi-square-honeycomb were analyzed and studied. The results show that both equivalent elastic modules are approximately equal, but the quasi-square-honeycomb sandwich structure is endowed with higher equivalent shear modulus and lower equivalent body density, thus the total structure mass can be effectively reduced. Simulation verifies the correctness of the proposed mechanical equivalent model of the quasi-square-honeycomb sandwich structure.
\end{abstract}

Keywords: Sandwich Structure, Quasi-Square-Honeycomb, Energy Method, Equivalent Elastic Constant, Mechanical Property

\section{Introduction}

As the world continues to exploit and consume energy sources, shortages and pollution to the environment and other issues become increasingly prominent. Energy-saving and environment- friendly product meets increasingly high requirements. Lightweight technology came into being, and the sandwich composite is developing rapidly in recent years. Because of its large specific stiffness and light weight, in recent decades, it has been widely used in the aerospace, automotive, aerospace, shipbuilding, etc. Sandwich structure is made of two high strength thin surface layers in which the intermediate sandwich layer fills. The intermediate uses new adhesive to bond formed.

Surface commonly uses metal, glass, steel, high hardness lightweight materials, while sandwich generally uses the honeycomb structure which is made of foam, aluminum, stainless steel, corrugated steel or other metals. Among them, the most common appliance is aluminum honeycomb. Honeycomb structures first originate in bionics. So far, sandwich materials have become the typical represent of high efficiency, energy-saving composites.

With the popularization and application of sandwich material in engineering, more stringent requirements for sandwich material specific stiffness, strength, stability, heat resistance, fatigue resistance, structure, size and other performance indicators were made in engineering applications. Traditional sandwich materials including honeycomb sandwich material has been increasingly unable to meet the design requirements. Therefore, it's an urgent need to develop 
new sandwich materials. According to the reports, the proposed new cellular sandwich configuration is of great innovative significance and value in engineering.

\section{Quasi-Square-Honeycomb Sandwich Structure Innovative Configuration}

Sandwich is an important part of the sandwich structure, and the appropriate sandwich structure can reduce a large degree of the weight of the sandwich structure. Based on the basis of previous studies [1-6], a new sandwich structure, "quasi-square-honeycomb sandwich structure", was presented from the perspective of bionics and innovative configurations in this paper. It conducted a detailed analysis of the mechanical properties and showed better structural characteristics of quasi-square-honeycomb sandwich layer by examples.

\subsection{The Overall Structure of Quasi-Square-Honeycomb Sandwich}

In the design of honeycomb sandwich structure, while taking into account the structure of the molding process and other factors, the decision is to use the following configurations:

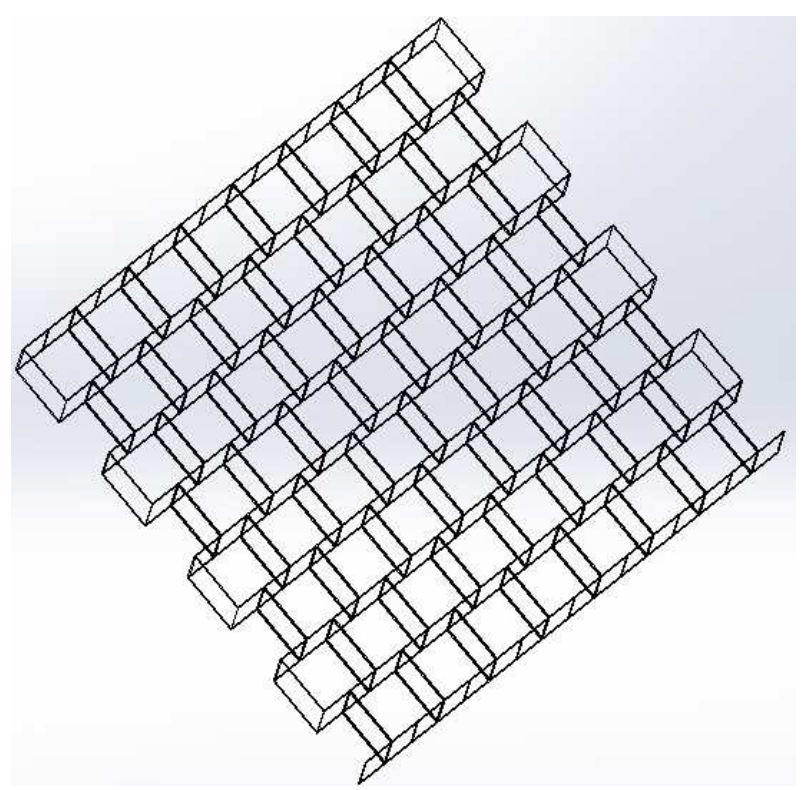

Figure 1. Quasi-square-honeycomb sandwich innovative configuration.

(1) Structural molding raw materials is the plate meeting the design requirements, molding and get arcuate repeating structural units.

(2) Use new energy saving adhesive to bond individual structural units in a symmetrical form and compose the desired quasi-square-honeycomb structure.

\subsection{The Size of Unit Division of Quasi-Square-Honeycomb Structure}

From the early Allen simplified model to the current widely used Gibson's [7] unit cell theory, the derivation of mechanical parameters model for the sandwich structure has been constantly improved. Until now, researches related to the equivalent elastic modulus parameters of the honeycomb structure at home and abroad mostly unfolded on the basis of unit cell theory [8-9]. As shown in figure 2, quadrangle surrounded by a dotted line is the unit cell, referred to herein as "T Model". The geometry of the unit cell is respectively length $h$, width $l$ and thickness $t$.

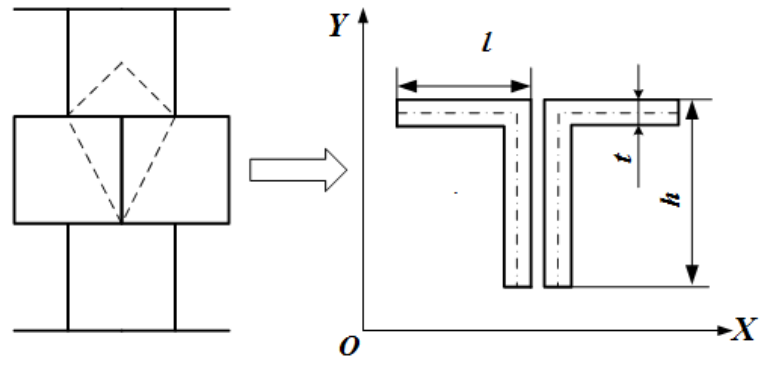

Figure 2. The structure and size of quasi-square-honeycomb unit cell.

\section{The elastic modulus $E_{\mathrm{cx}}$ and $E_{\mathrm{cy}}$}

\subsection{Deducing of $E_{\mathrm{cx}}$}

As shown in figure 3, force diagrams of quasi-square-honeycomb unit cells in the $\mathrm{X}$ direction, and the equivalent body is the rectangle surrounded by a dotted line. Take $t=b$ as the thickness of a quasi-square-honeycomb unit cell to research.

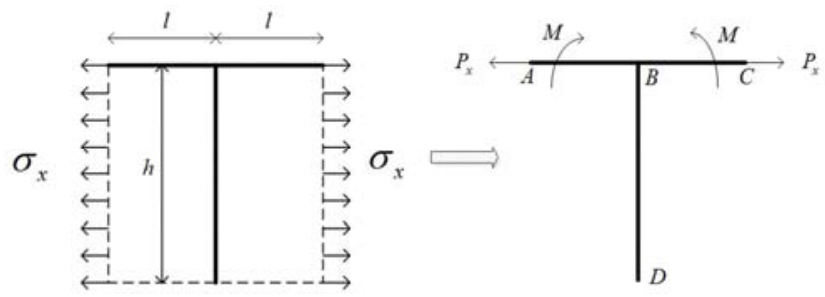

Figure 3. Positive stress force diagrams of the unit cell in the $X$ direction.

Due to the knowledge of mechanics of materials:

$$
E_{\text {cy }}
$$

Take torque to point $\mathrm{B}$, which is $\sum \mathrm{M}$ (B), and then $\mathrm{M}=0$ can be obtained.

The strain energy of the equivalent body:

$$
\overline{\mathrm{U}}=\frac{1}{2} \sum_{\mathrm{i}=1}^{\mathrm{n}} \frac{P_{n i}^{2}}{E_{\mathrm{i}}} \frac{\mathrm{L}_{\mathrm{i}}}{\mathrm{A}_{\mathrm{i}}}=\frac{\partial_{\mathrm{x}}^{2} \mathrm{hbl}}{\mathrm{E}_{\mathrm{cx}}}=\frac{\partial_{\mathrm{x}}^{2}}{2 \mathrm{E}_{\mathrm{cx}}} \mathrm{V}
$$

The actual deformation energy by the $\mathrm{AB}, \mathrm{BC}, \mathrm{CD}$ composition, the axial tensile deformation energy of the $\mathrm{AB}$, $\mathrm{BC}$ cell wall is:

$$
\mathrm{U}_{\mathrm{AB}}=\frac{1}{2} \sum_{\mathrm{i}=1}^{\mathrm{n}} \frac{1}{2} \frac{\mathrm{P}_{\mathrm{ni}}^{2}}{\mathrm{E}_{\mathrm{i}}} \frac{\mathrm{L}_{\mathrm{i}}}{\mathrm{A}_{\mathrm{i}}}=\frac{1}{2} \frac{\mathrm{P}_{\mathrm{x}}{ }^{2} \mathrm{l}}{\mathrm{E}_{\mathrm{s}} \mathrm{bt}}
$$




$$
\mathrm{U}_{\mathrm{BC}}=\mathrm{U}_{\mathrm{AB}}=\frac{1}{2} \frac{\mathrm{P}_{\mathrm{x}}{ }^{2} \mathrm{l}}{\mathrm{E}_{\mathrm{s}} \mathrm{bt}}
$$

The total strain energy of the axial direction:

$$
\mathrm{U}_{1}=\mathrm{U}_{\mathrm{AB}}+\mathrm{U}_{\mathrm{BC}}=\frac{\mathrm{P}_{\mathrm{x}}{ }^{2} 1}{\mathrm{E}_{\mathrm{s}} \mathrm{bt}}
$$

So from the $\bar{U}=U_{1}$ get:

$$
\mathrm{E}_{\mathrm{cx}}=\frac{\mathrm{E}_{\mathrm{s}} \mathrm{t}}{\mathrm{h}}
$$

\subsection{Deducing of $E_{\mathrm{cy}}$}

As shown in figure 4, force diagrams of quasi-square-honeycomb unit cells in the $\mathrm{Y}$ direction, and the equivalent body is the rectangle surrounded by a dotted line. Also take $t=b$ as the thickness of a quasi-square-honeycomb unit cell as research object.

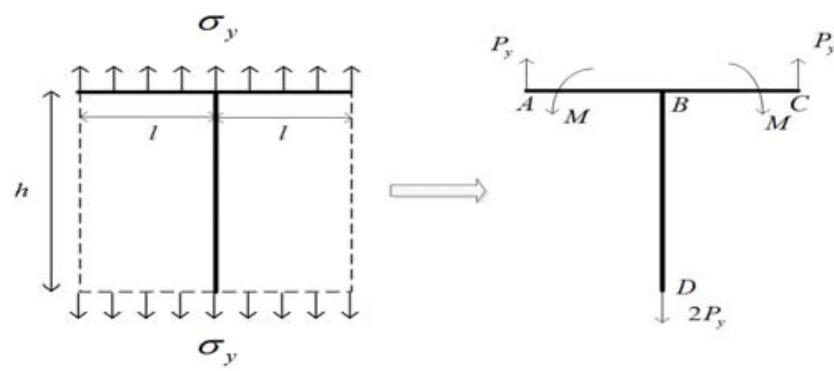

Figure 4. Positive stress force diagrams of the unit cell in the Y direction.

Due to the knowledge of mechanics of materials:

$$
\mathrm{P}_{\mathrm{y}}=\partial_{\mathrm{y}} \mathrm{bl}
$$

Take torque to point $\mathrm{B}$, which is $\sum \mathrm{M}$ (B), and then $\mathrm{M}=\frac{\mathrm{P}_{\mathrm{y}} 1}{2}$ can be obtained.

The strain energy of equivalent body:

$$
\overline{\mathrm{U}}=\frac{1}{2} \sum_{\mathrm{i}=1}^{\mathrm{n}} \frac{\mathrm{P}_{\mathrm{ni}}^{2} \mathrm{l}_{\mathrm{i}}}{\mathrm{E}_{\mathrm{i}} \mathrm{A}_{\mathrm{i}}}=\frac{\partial_{\mathrm{y}}^{2} \mathrm{~V}}{2 \mathrm{E}_{\mathrm{cy}}}
$$

The actual deformation energy by the $\mathrm{AB}, \mathrm{BC}, \mathrm{CD}$ composition, the bending strain energy of the $\mathrm{AB}, \mathrm{BC}$ cell wall is:

$$
\begin{gathered}
\mathrm{U}_{\mathrm{AB} 2}=\int_{0}^{1} \frac{\left(\mathrm{P}_{\mathrm{y}} \mathrm{x}-\mathrm{M}\right)^{2}}{2 \mathrm{E}_{\mathrm{s}} \mathrm{I}} \mathrm{dx}=\frac{\partial_{\mathrm{y}}^{2} \mathrm{bl} \mathrm{l}^{5}}{2 \mathrm{E}_{\mathrm{s}} \mathrm{t}^{3}} \\
\mathrm{U}_{\mathrm{BC} 2}=\mathrm{U}_{\mathrm{AB} 2}=\frac{\partial_{\mathrm{y}}^{2} \mathrm{bl}^{5}}{2 \mathrm{E}_{\mathrm{s}} \mathrm{t}^{3}}
\end{gathered}
$$

Where:

$$
I=\frac{b t^{3}}{12}
$$

The axial strain energy BD cell wall:

$$
\mathrm{U}_{\mathrm{BD}}=\frac{1}{2} \sum_{\mathrm{i}=1}^{\mathrm{n}} \frac{4 \mathrm{P}_{\mathrm{y}}^{2} \mathrm{~h}_{\mathrm{i}}}{\mathrm{E}_{\mathrm{i}} \mathrm{A}_{\mathrm{i}}}=\frac{2 \partial_{\mathrm{y}}^{2} \mathrm{l}^{2} \mathrm{hb}}{\mathrm{E}_{\mathrm{s}} \mathrm{t}}
$$

The sum of bending strain energy and axial strain energy is: The bending strain energy:

$$
\mathrm{U}_{1}=\mathrm{U}_{\mathrm{AB} 2}+\mathrm{U}_{\mathrm{BC} 2}=\frac{\partial_{\mathrm{y}}^{2} \mathrm{bl}^{5}}{\mathrm{E}_{\mathrm{s}} \mathrm{t}^{3}}
$$

The axial strain energy:

$$
\mathrm{U}_{2}=\mathrm{U}_{\mathrm{BD}}=\frac{2 \partial_{\mathrm{y}}^{2} \mathrm{l}^{2} \mathrm{hb}}{\mathrm{E}_{\mathrm{s}} \mathrm{t}}
$$

So from the $\bar{U}=U_{1}+U_{2}$ get:

$$
E_{c y}=\frac{E_{s} h t^{3}}{1\left(1^{3}+2 h t^{2}\right)}
$$

\section{The Elastic Modulus $G_{c x y}$}

According to the analysis, the stress state of the calculation model is necessary to meet unit cell balance, but also to meet the balance of the entire sandwich that each node balancing. The forces equivalent model is shown in Figure 5. Build the model, and introduce a few assumptions:

1. Assume that A, B, C node has no relative displacement.

2. Assume that each node turned the same angle.

3. Shear deformation is formed by BE rotation around point $\mathrm{B}$ and its bend.
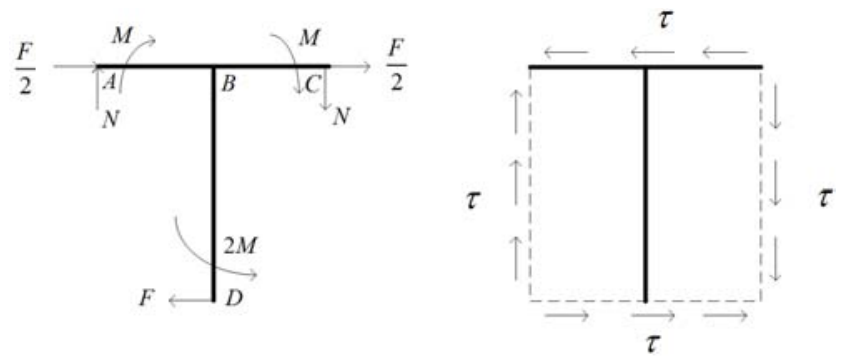

Figure 5. Shear force analysis diagram of the unit cell.

The entire structure take torque to point $\mathrm{B}$, because $\sum \mathrm{M}(\mathrm{B})=0$ : .

$$
\mathrm{Fh}=2 \mathrm{Nl}
$$

It is found that:

$$
\mathrm{N}=\frac{\mathrm{Fh}}{21}
$$

By shear stress equivalent reciprocal theorem of an 
equivalent unit structure, it can be obtained that:

$$
\tau=\frac{\mathrm{F}}{2 \mathrm{bl}}=\frac{\mathrm{N}}{\mathrm{bh}}
$$

The stress analysis unit, $\mathrm{AB}$ wall, takes torque to point $\mathrm{B}$, which is $\sum \mathrm{M}(\mathrm{B})=0$.

$$
\mathrm{M}=\frac{\mathrm{Fh}}{4}
$$

The deformation energy of equivalent unit body is:

$$
\overline{\mathrm{U}}=\frac{\tau^{2} \mathrm{~V}}{2 \mathrm{G}_{\mathrm{cxy}}}
$$

Due to the relationship between the forces on the graph, the $\mathrm{AB}, \mathrm{BC}, \mathrm{BD}$ bending strain is:

$$
\begin{gathered}
\mathrm{U}_{\mathrm{BD} 1}=\int_{0}^{\mathrm{h}} \frac{(\mathrm{Fx}-2 \mathrm{M})^{2}}{2 \mathrm{E}_{\mathrm{s}} \mathrm{I}} \mathrm{dx}=\frac{\mathrm{F}^{2} \mathrm{~h}^{3}}{2 \mathrm{E}_{\mathrm{s}} \mathrm{bt}^{3}} \\
U_{\mathrm{BC} 1}=\int_{0}^{l} \frac{(N x+M)^{2}}{2 E_{S} I} \mathrm{dx}=\frac{5 F^{2} h^{2} l}{4 E_{s} b t^{3}} \\
\mathrm{U}_{\mathrm{AB} 1}=\int_{0}^{1} \frac{(N x+M)^{2}}{2 \mathrm{E}_{\mathrm{s}} \mathrm{I}}=\frac{5 F^{2} h^{2} l}{4 E_{s} b t^{3}}
\end{gathered}
$$

Where:

$$
\mathrm{I}=\frac{\mathrm{bt} \mathrm{t}^{3}}{12}
$$

And $\mathrm{AB}, \mathrm{BC}$ axial elongation strain energy is:

$$
\begin{gathered}
\mathrm{U}_{\mathrm{AB} 2}=\frac{\left(\frac{\mathrm{F}}{2}\right)^{2} l}{2 \mathrm{E}_{\mathrm{S}} \mathrm{A}}=\frac{F^{2} l}{8 E_{s} b t} \\
U_{B C 2}=U_{A B 2}=\frac{F^{2} l}{8 E_{s} b t}
\end{gathered}
$$

Axial deformation energy of the equivalent body is:

$$
\mathrm{U}_{2}=\mathrm{U}_{\mathrm{AC} 2}+\mathrm{U}_{\mathrm{BC} 2}=\frac{\mathrm{F}^{2} 1}{4 \mathrm{E}_{\mathrm{s}} \mathrm{bt}}
$$

Bending deformation energy of the equivalent body is:

$$
\mathrm{U}_{1}=\mathrm{U}_{\mathrm{AB} 1}+\mathrm{U}_{\mathrm{BC} 1}+\mathrm{U}_{\mathrm{BD} 1}=\frac{\mathrm{F}^{2} \mathrm{~h}^{2}(51+\mathrm{h})}{2 \mathrm{E}_{\mathrm{s}} \mathrm{bt}^{3}}
$$

Therefore

$$
\overline{\mathrm{U}}=\mathrm{U}_{1}+\mathrm{U}_{2}=\frac{\mathrm{F}^{2}\left(10 \mathrm{~h}^{2} 1+2 \mathrm{~h}^{3}+\mathrm{lt}^{2}\right)}{4 \mathrm{E}_{\mathrm{s}} \mathrm{bt}^{3}}
$$

Shear modulus is as follows:

$$
G_{c x y}=\frac{E_{s} t^{3}}{1 h(2 h+101)}
$$

\section{Equivalent Density}

The idea to calculate the density of equivalent body of structure models is to calculate quality of quasi-square-honeycomb cell wall, then compare with the equivalent entities whose cell wall is the same size. Thereby, obtain a density of the equivalent body.

Physical volume of cell wall is:

$$
\mathrm{V}_{\mathrm{s}}=b t(h+2 l)
$$

Entity quality:

$$
m_{s}=\rho_{s} V_{s}
$$

Volume of the equivalent body is:

$$
\mathrm{V}_{\mathrm{c}}=2 \mathrm{lhb}
$$

So density of the equivalent body is:

$$
\rho_{\mathrm{c}}=\frac{\mathrm{m}_{\mathrm{s}}}{\mathrm{V}_{\mathrm{c}}}=\frac{\rho_{\mathrm{s}}(2 \mathrm{lbt}+\mathrm{hbt})}{2 \mathrm{lhb}}=\frac{\rho_{\mathrm{s}}(2 \mathrm{lt}+\mathrm{ht})}{2 \mathrm{hl}}
$$

By the principle of conservation of mass, mass of the equivalent body is as follows:

$$
\mathrm{m}_{\mathrm{c}}=\mathrm{m}_{\mathrm{s}}=\rho_{\mathrm{s}}(2 \mathrm{lbt}+\mathrm{hbt})
$$

The above derivation can introduced the quasi-square-honeycomb equivalent mechanical parameters in engineering application, which are as follows:

$$
\left\{\begin{array}{l}
E_{c x}=\frac{E_{s} t}{h} \\
E_{c y}=\frac{E_{s} h t^{3}}{l\left(l^{3}+2 h t^{2}\right)} \\
G_{\mathrm{cxy}}=\frac{E_{s} h t^{3}}{l\left(2 h^{3}+26 h^{2} l+\mathrm{lt}^{2}\right)} \\
\rho_{c}=\frac{\rho_{s}(2 l t+h t)}{2 h l}
\end{array}\right.
$$

Where in meanings of each symbol are as follows: $\mathrm{b} 、 \mathrm{~h} 、 \mathrm{l}, \mathrm{t}$ respectively represents eight, width, length, thickness of quasi-square-honeycomb sandwich; $E_{c x}, E_{\text {cy }}$ represent equivalent elastic modulus of quasi-square -honeycomb sandwich in the $\mathrm{X}, \mathrm{Y}$ direction, $M P a ; E_{s}$ represents modulus of elasticity of the core material, $M P a$; $G_{c x y}$ represents equivalent shear modulus of quasi-square-honeycomb sandwich in the $x y$ plane, $M P a$; $\rho_{c}$ represents equivalent density of quasi-square-honeycomb sandwich, $\mathrm{kg} / \mathrm{m}^{3} ; \rho_{s}$ represents density of sandwich material, $\mathrm{kg} / \mathrm{m}^{3}$. 
To facilitate the process, choose $\mathrm{h}=21$, and actually the thickness $t$ of honeycomb is far less than the length 1 of the cell wall, then the above equations can be simplified as:

$$
\left\{\begin{array}{l}
E_{c x}=\frac{E_{s} t}{2 l} \\
E_{c y}=\frac{2 E_{s} t^{3}}{l^{3}+4 l t^{2}} \\
G_{c x y}=\frac{E_{s} t^{3}}{28 l^{3}} \\
\rho_{c}=\frac{\rho_{s} t}{l}
\end{array}\right.
$$

\section{Example Comparative}
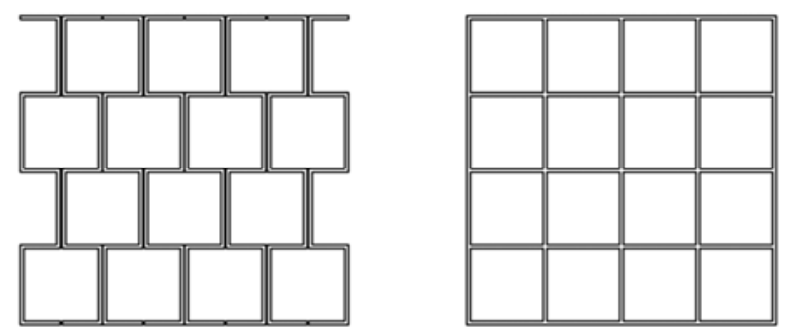

Figure 6. Quasi-square-honeycomb sandwich and square-honeycomb sandwich.

As shown in Figure 6, for square-honeycomb sandwich layer with the same thickness of unit cell, using the same method in Section 2 and Section 3, equivalent mechanical model parameters of square-honeycomb can be deduced:

$$
\left\{\begin{array}{l}
E_{c x}^{*}=\frac{E_{s} t}{2 l} \\
E_{c y}^{*}=\frac{2 E_{s} t^{3}}{l^{3}+2 t^{2} l} \\
G_{c y}^{*}=\frac{E_{s} t^{3}}{10 l^{3}} \\
\rho_{c}^{*}=\frac{3 \rho_{s} t}{2 l}
\end{array}\right.
$$

While $t<<l$, let $n$ as the ratio of the equivalent mechanical parameters corresponding to quasi-square-honeycomb structure and square-honeycomb structure, and you can get the following results:

$$
\left\{\begin{array}{l}
n_{E_{C X}}=E_{c x} / E_{c x}^{*} \approx 1 \\
n_{E_{c y}}=E_{c y} / E_{c y}^{*} \approx 1 \\
n_{G_{c y}}=G_{c x y} / G_{c y}^{*} \approx 0.36 \\
n_{\rho_{c}}=\rho_{c} / \rho_{c}^{*} \approx 0.67
\end{array}\right.
$$

$\operatorname{Order} \beta=l / t$, since $t / l$ is the main design parameters of honeycomb sandwich structure and usually $t / l \in(1 / 10,1 / 100)$, it can be obtained that $\beta \in(10,100)$. Substitute $\beta$ into formula (34) and (35) and study the changes of equivalent mechanical performance parameters.

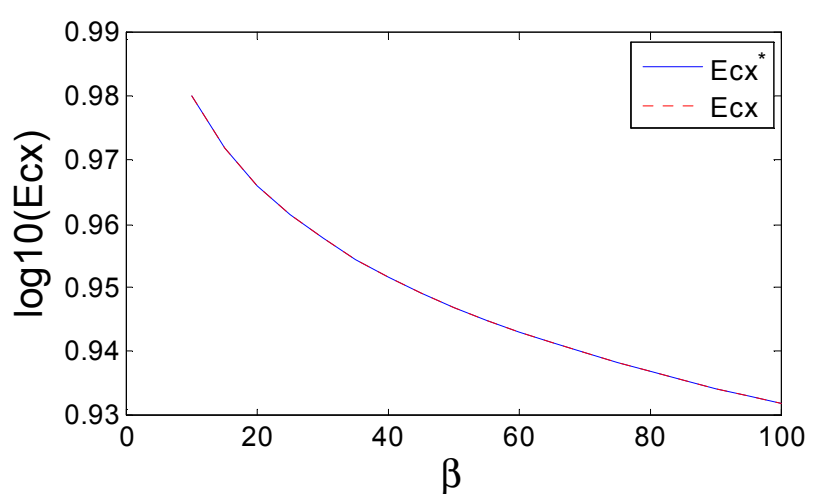

Figure 7. The contrast of equivalent elastic modulus of two kinds of honeycomb sandwiches in the $x$ direction.

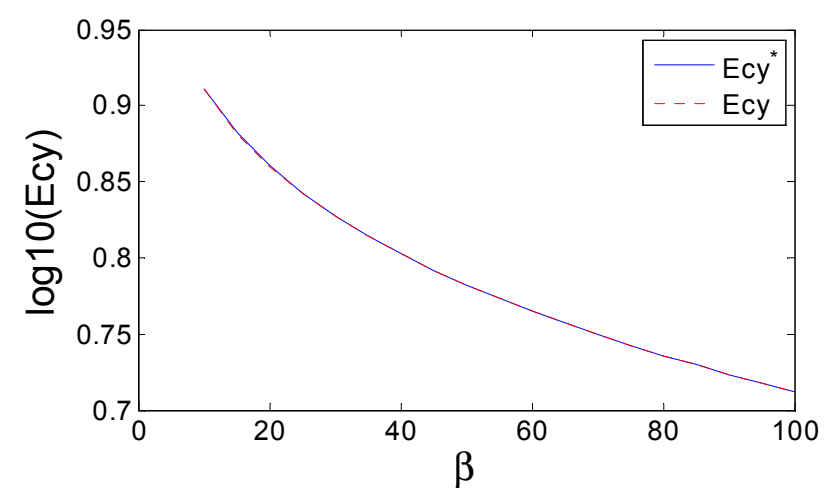

Figure 8. The contrast of equivalent elastic modulus of two kinds of honeycomb sandwiches in the $Y$ direction.

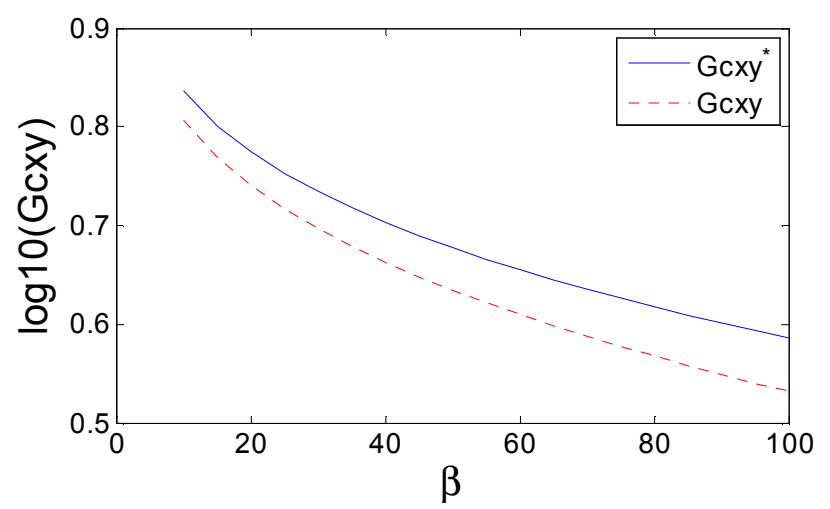

Figure 9. The contrast of equivalent shear modulus of two kinds of honeycomb sandwiches.

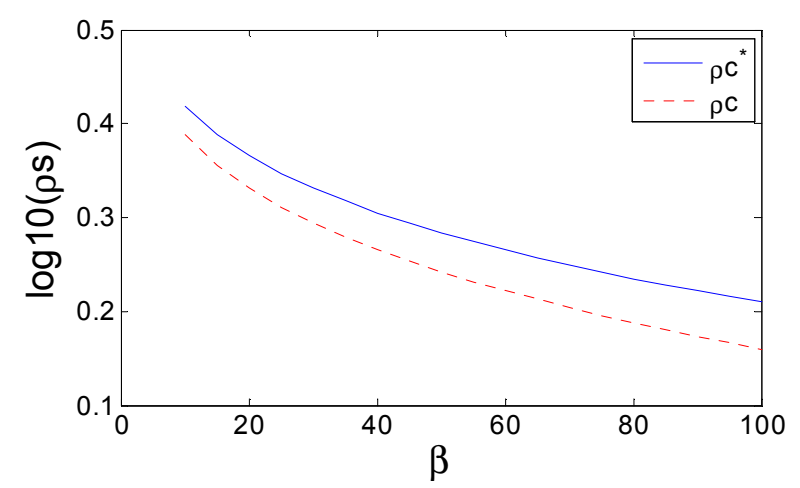

Figure 10. The contrast of equivalent densities of quasi-square-honeycomb and square-honeycomb. 
As can be seen from Figure 7-10, the elastic modulus of quasi-square-honeycomb almost coincide with square-honeycomb, and its shear modulus is less than square-honeycomb and its equivalent density is much less than square-honeycomb.

Table 1. Structure parameters of honeycomb sandwich plate in satellite structure.

\begin{tabular}{|c|c|c|}
\hline Panel thickness $\mathrm{t}_{\mathrm{f}}(\mathrm{mm})$ & \multicolumn{2}{|c|}{ Sandwich thickness b(mm) } \\
\hline 0.3 & 24.4 & \\
\hline Panel material (aluminum) & $\mathrm{E}_{\mathrm{f}}(\mathrm{GPa})$ & 70 \\
\hline Sandwich unit cell size (mm) & t & 0.04 \\
\hline Sandwich material (aluminum) & Es (GPa) & 70 \\
\hline
\end{tabular}

Select honeycomb sandwich panels which are used on a satellite structure [10] as an example. The honeycomb panel's sandwich is aluminum honeycomb structure made of aluminum alloy 2024 material, and its yield strength is $758 \mathrm{MPa}$, density is $\rho_{s}=2780 \mathrm{Kg} / \mathrm{m}^{3}$, other data as shown in Table 1. According to the formula (34) and (35), it can respectively obtain equivalent elastic constants of quasi-square-honeycomb sandwich structure and square -honeycomb sandwich structure as shown in Table 2.

Table 2. Mechanical properties parameters of quasi-square-honeycomb and square -honeycomb sandwich structure.

\begin{tabular}{lll}
\hline sandwich structure & $E_{c x}(\mathbf{M P a})$ & $E_{c y}(\mathbf{M P a})$ \\
\hline quasi-square-honeycomb sandwich & 350 & 0.14 \\
square -honeycomb sandwich & 350 & 0.14 \\
sandwich structure & $G_{c x y}(\mathrm{~Pa})$ & $\rho_{c}\left(\mathrm{~kg} / \mathrm{m}^{3}\right)$ \\
quasi-square-honeycomb sandwich & 2500 & 27.8 \\
square -honeycomb sandwich & 7000 & 41.7 \\
\hline
\end{tabular}

The establishment conditions of above formulas are that each cell thickness $t$ is equal. From equation (36), it can be seen that the equivalent elastic modulus of quasi-square-honeycomb is approximately equal to squarehoneycomb. Although its shear modulus is less than squarehoneycomb, its density is much less than square- honeycomb, which shows that under the same circumstances its quality is far less than square-honeycomb. Otherwise, compared to square-honeycomb, the manufacturing process of quasi-square-honeycomb is more convenient.

\section{Numerical Simulations}

In order to verify the correctness of the formula (34), choose ANSYS simulation analysis to simulate the quasi-square-honeycomb sandwich parameters. Its finite element model is shown in Figure 11.

Setting material properties for the AL2024 aluminum alloy, the yield strength of the material is $758 \mathrm{MPa}$. Take $3 \mathrm{~mm} \times$ $6 \mathrm{~mm} \times 10 \mathrm{~mm}$ quasi-square-honeycomb sandwich structure; Respectively exert stress of finite element simulation in the direction of $\mathrm{x}, \mathrm{y}$ and $\mathrm{z}$, results shown in Figure 12-14.

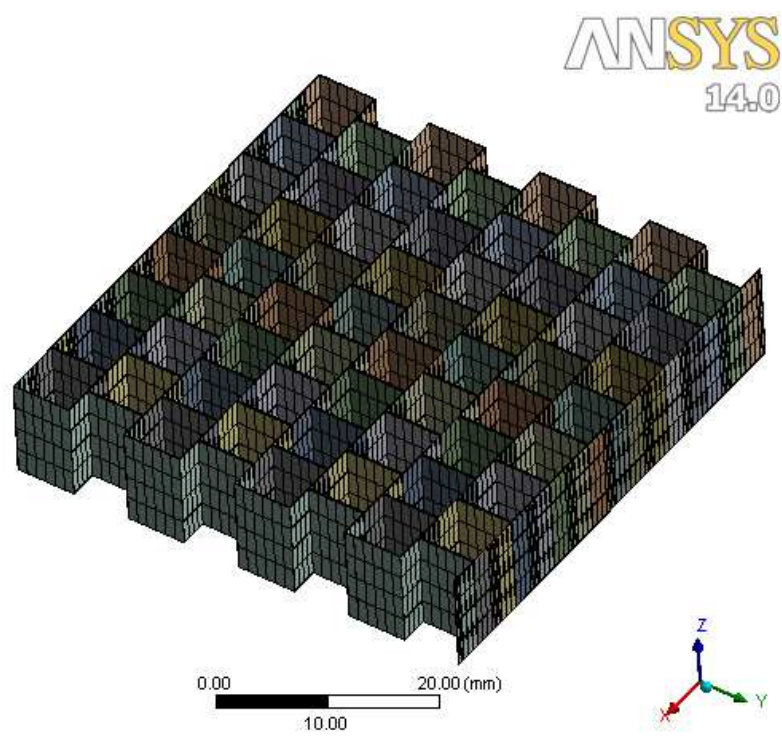

Figure 11. Finite element model of quasi-square-honeycomb sandwich.

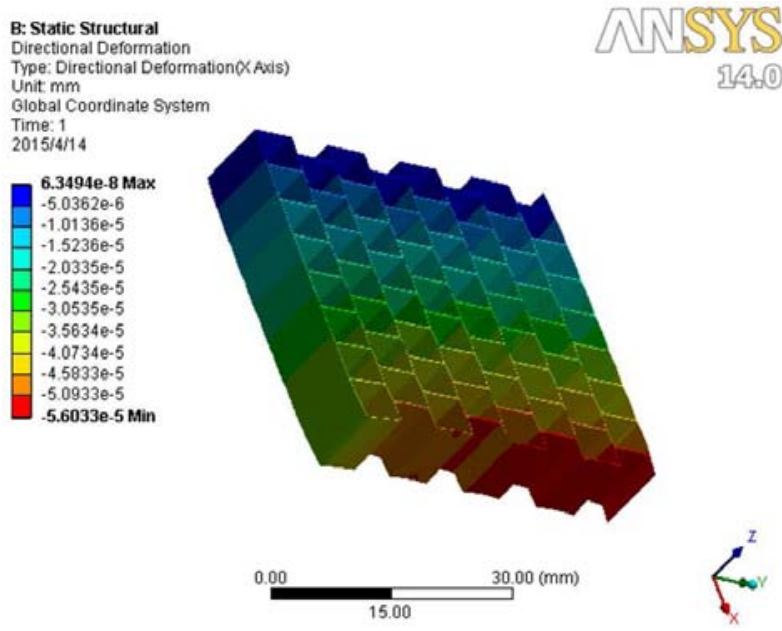

Figure 12. Displacement contours in X direction.

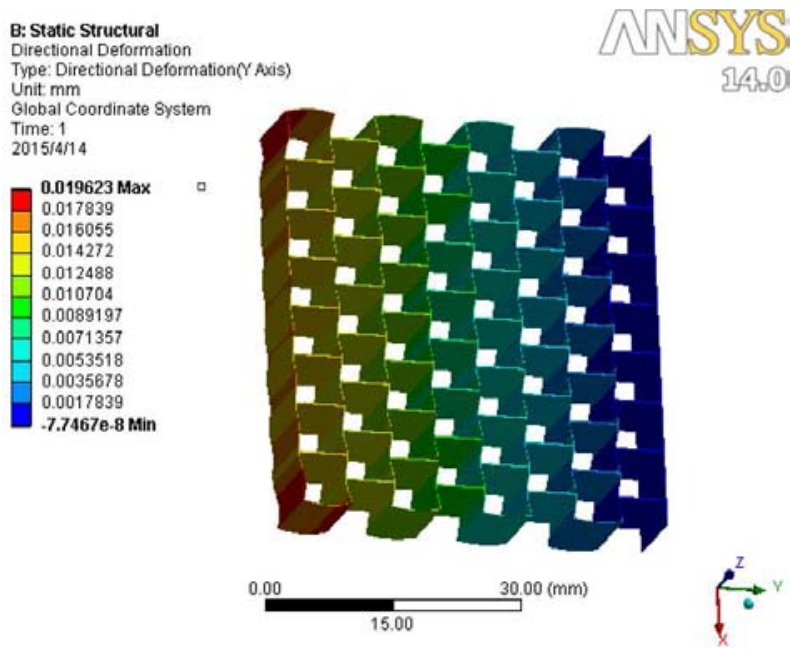

Figure 13. Displacement contours in Y direction. 


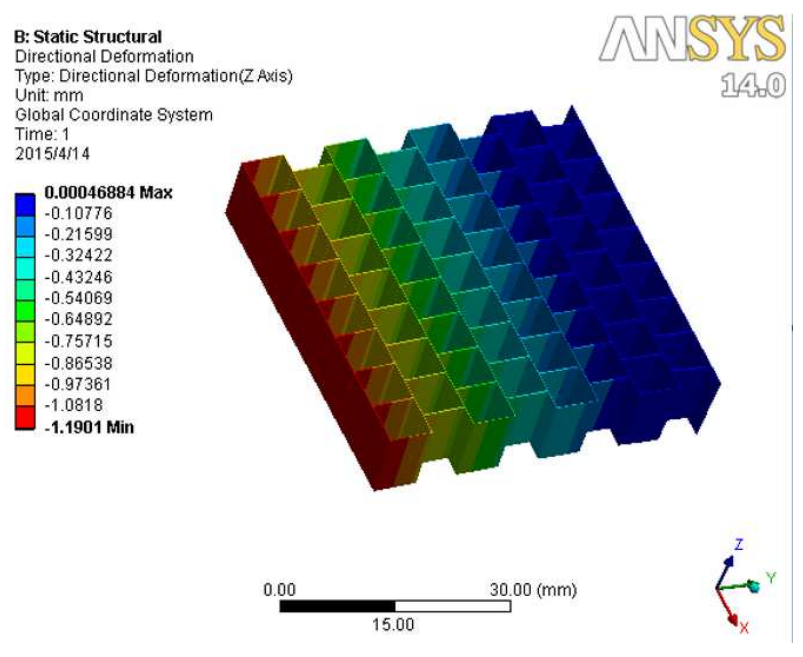

Figure 14. Equivalent stress contours.

According to theoretical calculations and simulation analysis, the elastic constants of quasi-square-honeycomb equivalent model are obtained (Table 3 ). As can be seen from the table, theoretical calculations and simulation results are consistent, thereby it validated quasi-square-honeycomb equivalent mechanical model.

Table 3. Comparison of elastic constants of the equivalent mechanical model.

\begin{tabular}{llll}
\hline Results & $\mathbf{E}_{\mathbf{c x}} / \mathbf{G P a}$ & $\mathbf{E}_{\mathbf{c y}} / \mathbf{M P a}$ & $\mathbf{E}_{\mathbf{c x y}} / \mathbf{M P a}$ \\
\hline Simulation values & 1.1833 & 5.5260 & 0.0251 \\
Theoretical values & 1.1667 & 5.1852 & 0.0926 \\
\hline
\end{tabular}

\section{Conclusions}

Based on the relevant findings of quasi-honeycomb structure composite [11], it improved the common traditional square-honeycomb, proposed a new quasi-square-honeycomb structure. On this basis, using Gibson's classical theory of unit cells and energy method, it carried out a detailed analysis and derivation, analyzed the comparison of equivalent mechanical properties of quasi-square-honeycomb and square-honeycomb, combined finite element analysis and verified its correctness. Studies have shown that the mechanical properties of the improved new quasi-square-honeycomb sandwich structure are better than conventional square-honeycomb sandwich structure.

\section{Acknowledgements}

The authors are very grateful for the financial supports of the National Natural Science Foundation of China: "Innovating configuration and integrated design method of structure-material properties for ultralight and porous class-honeycomb sandwich structure material" (51305232), Open Fund of Hubei Key Laboratory of Hydroelectric Machinery Design \& Maintenance (2012KJX07), Doctoral Start-up funding scientific research projects of China Three Gorges University (KJ2012B015) and Hubei Provincial Natural Science Foundation (2012FFC016).

\section{References}

[1] D. Zenkert. The Handbook of Sandwich Construction [M]. London: EMAS Publishing.

[2] Xiang Li, Gangyan Li, Chun H. Wang and Min You. Minimum-Weight Sandwich Structure Optimum Design Subjected to Torsional Loading [J]. Applied Composite Materials, 2012, 19: 117-126.

[3] Xiang Li, Gangyan Li, Chun H. Wang and Min You. Optimum design of composite sandwich structures subjected to combined torsion and bending loads [J]. Applied Composite Materials, 2012, 19: 315-331.

[4] LI Xiang, LI Gangyan, You Min, et al. Sandwich structure lightweight design subjected to multiple loading constraints and its application $[\mathrm{J}]$. Journal of Wuhan University of Technology, 2011, 33 (8): 138-141.

[5] Li Xiang, You Min. Mechanical property analysis and numerical simulation of honeycomb sandwich structure's core [J]. Advanced Materials Research, 631-632: 518-523, 2013.

[6] Gibson, L. J. Modelling the Mechanical Behavior of Cellular Material [J]. Master Science and Engineering. 1989, A110: $1-36$.

[7] ALLEN H G. Analysis and Design of Structural Panels [M]. Oxford: Pergamon Press, 1969.

[8] FU Minghui, YIN Jiuren. Equivalent elastic parameters of the honeycomb core [J]. Acta Mechanica Sinica, 1999, 31 (1): 113-118.

[9] LIANG Sen, CHEN Hua-ling, CHEN Tian-ning, et al. Analytical study of the equivalent elastic parameters for a honeycomb core [J]. Journal of Aeronautical Materials, 2004, 24 (3): $26-31$.

[10] LI Xiang, YOU Min. Mechanics performance analysis and numerical simulation of sandwich structure's core for satellite [J]. Journal of China Three Gorges University: Nature Sciences, 2012, 34 (4): 77-80.

[11] LI Xiang, Zhou Youhui, Tong Guan, Yu Licheng, Li Yang, Zhang Xun. Innovating Configuration and Mechanical Properties of the Core for Ultralight and Porous QuasiHoneycomb Sandwich Structure. Journal of Xi'an JiaoTong University [J]. 2014, 48 (9): 88-94. 